\title{
The conceptual model of Personal Moral Philosophy (PMP) and Ethical Decision Making (EDM)
}

\author{
Ling Meng Chan \\ Dept of Business, Universiti Tunku Abdul Rahman \\ Jalan University, Bandar Barat \\ 31900 Kampar, Perak
}

Tel: 05-468-8888Ｅ-mail: chanlm@utar.edu.my

Dr. Jamilah Othman (Corresponding author)

Dept of Professional Development and Continuing Education, Universiti Putra Malaysia

Universiti Putra Malaysia, 43400 UPM, Serdang, Selangor, Malaysia

Tel: 60-3-8946-6000Ｅ-mail: jamilah@educ.upm.edu.my

Assoc. Professor Rusinah bte Joned (Corresponding author)

Dept of Professional Development and Continuing Education, Universiti Putra Malaysia

Universiti Putra Malaysia, 43400 UPM, Serdang, Selangor, Malaysia

Tel: 60-3-8946-6000Ｅ-mail: rusinah@putra.upm.edu.my

Received: June 27, 2011 Accepted: June 30, 2011 doi:10.5296/jmr.v3i2.752

\begin{abstract}
The purpose of this study is to develop a conceptual model to examine the two dimensions of personal moral philosophy (Idealism and Relativism) and its influences on the Ethical Decision Making. The study use the Forsyth's Taxonomy of Personal Moral Philosophy and the Rest's Ethical Decision Making Model serves as the starting points to develop the conceptual model. Two dimensions of personal moral philosophy and 4 main components of Ethical Decision Making were used to construct the model from the extensive literature. The developed model will provide the base for assessing the level of Ethical Decision Making by studying the influences of the level of PMP. This finding further the insight of the understanding of the philosophical and ethical analysis of managerial dilemmas. The model
\end{abstract}




\section{Macrothink

provides an insightful for the analysis of personal moral philosophy on Ethical Decision Making. The model examines the independent influences of personal moral philosophy on Ethical Decision Making and treats Ethical Decision Making as dependent variables. Given that Ethical Decision Making are often detrimental to organizational functional efficiency, it is appropriate for the management to have better understanding to diagnose effects of the personal moral philosophy on the Ethical Decision Making. For this analysis, this model will prove valuable.

Keywords: Ethical decision making, personal moral philosophy, idealism, relativism 


\section{Introduction}

As the management problems become more complex, they become more ethical. As management problems become more ethical, they become more complex, as quoted by Peterson, Rhoads, \& Vaught, (2001). The corporate senior executives are placed under extreme pressure to balance shareholder earnings against corporate social responsibility. However, the price fixing, the savings and load scandals, and numerous insider trading prosecutions have harmed the public's perception of business ethics. As stated by Yvonne, Jeanne \& Rafik (2004), as the economic develop and business become more interdependent across the globe, the potential for ethical or moral problems that have to be addressed by management has been increasing. Such managerial dilemmas result from the need to maintain a "right" or "proper" or "just” balance between economic and social performance: economic analysis, legal analysis, and philosophies, ethical analysis. Economic analysis focuses on market forces, revenue maximization and cost minimization whereas legal analysis is based on impersonal social and political processes and assumes that in a democracy laws represents the collective moral judgment of members of a society and must always be obeyed. Although useful, both analyses have serious theoretical and practical shortcomings. Philosophic, ethical analysis is also associated with some problem, but perhaps not as serious as in other types of analysis. Philosophies, ethical analysis is based on rational thought processes, "moral reasoning” (Ardagh \& Macklin, 1998; Tom L. Beauchamp \& Bowie, 2004; Butterfield, Trevino, \& Weaver, 2000; Chen, Pan, \& Pan, 2009)

Nowadays, managers must be able to address moral, ethical dilemmas that result from an imbalance between economic and social performance as argued by Yvonne, Jeanne \& Rafik (2004). On top of it, managers also need to develop a thorough understanding of how to conduct a philosophical, ethical analysis. It is crucial to understand the ethical behavior in business, as when business are charged with infractions or when employees come under legal investigation, there is a concern raised about moral behavior in business. Thus, the level of mutual trust nowadays is threatened.

As discussed as above, a point here that needs to be taken into consideration is that the ethical perception of managers' change and gets complicated by environmental factors such as culture, family, religion, managers and customs, values and demographic structure. In this stage, it is also observed that the management principles particular to the enterprise, standards and organizational culture affect the attitudes and behaviors of the managers in the decision making process. Hence, it may be said that some special factors based on the structure of each hotel enterprise are also influential in ethical decision making apart from some environmental variables particular to tourism sector. In parallel with the importance of the subject in this way, this study is aimed at finding which ethical approaches HR managers adopt when they make a decision (Malloy \& Fennell, 1998; Stevens, 2001).

This paper attempts to examine the previous researches and supplements this study by examining the relationship between each dimension of Personal Moral Philosophy and Ethical Decision Making. This conceptual paper is structured as follows: the author will review the literature pertaining to the model of Personal Moral Philosophy and Ethical Decision Making, followed by the explanation on the relationship between these two 
variables. This followed by the development of the propositions for the study. Next, the author will briefly describe the development of the conceptual research framework. Last but not least, the author will discuss the conclusion with the new ideas derived from this study and explain both the theoretical and managerial implications as well as the indication for the further research.

\section{Methodology}

The present literature review has two primary objectives: to extend the previous literature by reviewing the empirical ethical decision making and personal moral philosophy from 1986 to 2010. It serves as the information guidelines for authors to fulfill the second objective which is to identify the connection and relationship between these two variables. Furthermore, this review provides insight for further research of which variables have the most significant influences while making decision during ethical dilemma.

\subsection{The propositions development of Personal Moral Philosophy (PMP)}

As stated by Ferrell and Gresham (1985), they mentioned that most of ethics theorists came into a consensus acknowledgement toward a situation where individual face some morality dilemma, he or she may use their ethical guidelines or moral philosophies to serve as the benchmark to measure whether the decision is morally correct or morally wrong.

According to Bass, Barnett \& Brown (1998), one of the differences among the ethical theories of deontology, teleology, and scepticism is the extent to which the theories are relativistic or non - relativistic. Generally, most of the ethics theories recognized the personal moral philosophy as one of important elements for individual's ethical decision making process, like Ferrell and Gresham (1985) and Hunt and Vitell (1986) mentioned that personal moral philosophy as the core for the development of framework of ethical decision making process (Anusorn Singhapakdi, Vitell, \& Leelakuthanit, 1994). From the findings, they found that personal moral philosophy has great impact over the process of the ethical decision making, especially in the area of business ethics (D. R. Forsyth \& Nye, 1990; D. R. Forsyth, Nye, \& Kelley, 1988; Anusorn Singhapakdi, et al., 1994).

This study employ Forsyth's interaction model. Forsyth (1980; 1985; 1992; 2002) created the interactional model - Person $\mathbf{X}$ Situation model to address differences in the process of making judgments. He proposes that the model explains an individuals' evaluation of an ethical dilemma as an expression of a person's own integrated system ethics. Forsyth (1980) has argued that individual differences as predictors of moral judgments may be described most parsimoniously by taking into account the two basic dimensions of personal moral philosophies: Relativism and Idealism.

Forsyth (1980) has developed taxonomy of 2 X 2for moral philosophies based on these two dimensions. The taxonomy is presented in Figure 1 with a summary of the characteristics of "absolutist”, "Situationists”, “subjectivists”, and "Exceptionists” 


\begin{tabular}{|c|c|c|}
\hline & High Relativism & Low Relativism \\
\hline $\begin{array}{l}\text { High } \\
\text { Idealism }\end{array}$ & $\begin{array}{l}\text { Situationists } \\
\text { - } \text { Rejects moral codes } \\
\text { - } \text { Personal analysis of actions in } \\
\quad \text { each situation } \\
\text { - } \quad \text { Relativistic } \\
\text { - } \quad \text { Idealistic Skeptic }\end{array}$ & $\begin{array}{l}\text { Absolutists } \\
\text { - } \text { Accepts moral codes } \\
\text { - } \quad \text { Ethical decisions must not } \\
\text { harm others } \\
\text { - } \text { Deontologist }\end{array}$ \\
\hline $\begin{array}{l}\text { Low } \\
\text { Idealism }\end{array}$ & 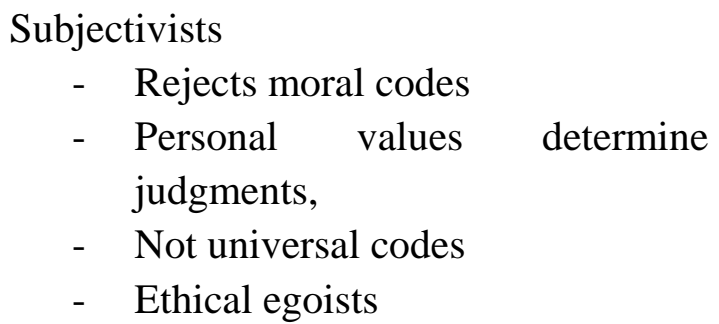 & $\begin{array}{l}\text { Exceptionists } \\
\text { - } \text { Accepts moral codes, but open } \\
\text { to exceptions. } \\
\text { - } \text { Optimal outcomes not possible } \\
\quad \text { for all } \\
\text { - } \\
\text { Teleologist, utilitarian }\end{array}$ \\
\hline
\end{tabular}

Figure 1.

Forsyth’s Taxonomy of Personal Moral Philosophies (S. J. Forsyth, 1980)

He terms the integrated system of ethics as "personal moral philosophy" (PMP), or "Ethical Ideology.” A person's moral beliefs, attitudes and values comprise his or her PMP, as stated by Forsyth (1980). In the PMP, it provides the guidelines for moral judgments, solutions to ethical dilemmas and prescriptions for actions in morally toned situations. It contains the distinctive elements produced by previous experiences in confronting and resolving ethical dilemmas. The model of PMP, in contrast with the Kohlberg's model of moral development, does not classify individuals are solely on the basis of their level of principles moral reasoning. The model of PMP represents a more general approach and therefore may be more useful, especially it focuses on the adult's moral judgments, as argued by Forsyth (2002).

As Forsyth (1980, p.175) states, relativism is the degree to which an individual rejects universal moral rules as appropriate guidelines for ethical decisions. Relativism contends that moral absolutes should be reject, and that moral rules exists in a situational context as a function of time, place and culture, as argued by Forsyth (1992). A person who is highly relativistic will believe that universal ethical codes or moral principles are not important when making ethical judgments, because he / she must consider the contextual factors. While, those low in relativistic will more stress on the importance of rigid adherence to ethical codes and moral absolutes when making moral judgments, as stated by Forsyth (1992).

Idealism (D. R. Forsyth, et al., 1988), involves the extend of an individual's concern with the welfare of others. This is the degree to which an individual believes that desirable consequences can, with the right action, always be obtained (S. J. Forsyth, 1980). An idealist believes that morally correct actions will often produce negative consequences as well as positive ones (S. J. Forsyth, 1980). Idealism describes the individuals' concern for the welfare of others. Highly idealistic individuals believe that harming others is always avoidable, and they would rather not choose between the lesser of two evils that will lead to the negative consequences for other people (Karande, Rao, \& Singhapakdi, 2002). Those who are less idealistic feel that harm is sometimes necessary to produce good (D. R. Forsyth, 1980, 1992; 
S. J. Forsyth, 1992). Idealism is not based on an embrace of moral absolutes; but yet it involves values related to altruism and a sense of optimism in considering responses to moral issues(A. Singhapakdi, Vitell, \& Franke, 1999). Hence, idealism and relativism are conceptually independent, and individuals maybe high or low on either dimensions. (S. J. Forsyth, 1980; Karande, et al., 2002)

The model of Forsyth's person moral philosophies rather that assuming individuals are either rule - oriented or consequences - oriented, assumes individuals can range from high to low in their emphasis on principles and in their emphasis on consequences. The model has identified the four district personal moral philosophies (D. R. Forsyth, 1992):

0

0

0

0
Situationism - relativistic and idealistic

Subjectivism - relativistic but not idealistic

Absolutism - not relativistic but idealistic

Exceptionism - neither relativistic nor idealistic

Situationism: Individuals who eschew universal moral principles (high in relativism) but still insist that one should produce positive consequences that benefits all involved (high in relativism) are known as situationist (D. R. Forsyth, 1992). Because these individuals favor the close inspection of potential benefits their outlook is most similar to philosophies approaches based on ethical skepticism (Forsyth, 1992)

Subjectivism: This type of individual rejects moral rules (high in relativism); however, they are not particularly positive about the possibility of achieving positive outcomes for everyone concerned (D. R. Forsyth, 1992). Because such individuals described their moral decisions as subjective, individualistic judgments that cannot be made on the basis of moral absolutes or the extent to which the action benefits others their viewpoint parallels an egoistic moral philosophy (D. R. Forsyth, 1992).

Absolutism: absolutists believe that one should strive to produce positive consequences (high in relativism) but at the same time maintain strict adherence to general moral principles (low in relativism) (D. R. Forsyth, 1992). According to Forsyth (1992), these individuals condemn certain actions, because they harm people and they violate fundamental moral absolutes.

Exceptionism: Exceptionists agree with the absolutist's appreciation of moral absolutes but they are not idealistic: they do not believe that harm can be avoided, that innocent people can always be protected, or that risking others' welfare is always wrong (Forsyth, 1992).

Forsyth (1980) pointed that absolutists were significantly harshly in their appraisals of actions that led to positive and negative consequences, he or she also particularly negative in their view in term of the morality issues, while idealists strongly condemned individuals who caused extremely negative consequences.

From the previous findings, authors concluded that differences in personal moral philosophies are significantly influence individuals toward the controversial ethical issues, especially in the field of business ethics. Past findings have shown that personal moral 
philosophy - the beliefs about the basis on which ethical decisions should be made is an important elements of attitudes towards the variety of social and ethics issues.

\subsection{The propositions development of Ethical Decision Making}

In the field of business, ethics is divided into two main major: the normative ethics and the descriptive ethics. Normative ethics is the guidelines or the theology to insight individuals as how should they behave while descriptive ethics is concerned on the explanation and prediction of human's behavior as stated by the past researchers (e.g. Donaldson and Dunfee, 1994; Trevino and Weaver, 1994). In this study, author mainly focuses on the literature review which pertaining with the descriptive ethical decision making. Most of the models of ethical decision making were built based on the Rest's (1986) framework which it consists of four main component in the process of ethical decision making - identify the moral issue raised, make moral judgment, establish moral intent and implement the moral action (Michael \& Kenneth, 2005).

Ethical decision making arises from two levels of moral reasoning: 1) the intuitive level consisting of one's personal feelings and ideas as to the "right" and "wrong” of a particular situation - feeling derived from beliefs formulated out of personal knowledge and experiences, and, 2) the critical evaluative level consisting of reasoned judgments and evaluations of the situation.

As to the application of moral reasoning to a given situation, one's intuitive response is always immediate and personal; it is our initial impression or gut feeling. It simply comes to us that this is correct or incorrect, right or wrong.

The critical evaluation level, on the other hand, is a decision we arrive at by applying ethical theory, moral principles and professional rules, standards, codes and laws to the specific situation which must be decided. Critical evaluation is seasoned thought.

Business ethics are rules, standards, or principles that provide guidelines for morality right behavior. Since values and ethics are so important to individual, group and corporate decisions, it is important that when two or more entities (individuals or groups) pursue joint goals they share the same value structure. Differences in ethics mean that underlying value structures differ, giving rises to potential conflicts regarding appropriate decisions and actions. Many of these rules applied when an individual is required to make a decision. (Carlson, Kacmar, \& Wadsworth, 2009). Thus, ethical decision making has become an area of research interest.

In 1991, Thomas Jones noted that many of the ethical decision making models to date (Dubinsky \& Loken, 1989; Ferrell \& Gresham, 1985; Hunt \& Vitell, 1986; Rest, 1986; Trevino, 1986) included a variety of the individual and situational characteristics noted earlier, but none included characteristics of the actual ethical issue itself. Without considering the influence of the characteristics of the ethical issues on the ethical decision making process, Jones noted, the models suggest that the process follows the same course for a dilemma involving the theft of a few supplies from the organization as it does for a dilemma involving the release of a dangerous product to market. Using Rest's (1986) parsimonious four 
component model as a foundation, Jones developed a model of ethical decision making that went beyond the models that focused on personal and situational characterizes by including a new construct that the labeled moral intensity, which consist of 6 characteristics of the moral issue.

The moral base or rules that are applied to determine right and wrong are often developed from one's cognitive moral development (Blasi, 1980; Fraedrich, Thorne, \& Ferrell, 1994; Kohlberg, 1969), value base (Musser \& Orke, 1992), or moral philosophies (T. L. Beauchamp \& Bowie, 1993; Cavanagh, Moberg, \& Velasquez, 1981). Hence, ethical decision making is a way of resolving conflicts where ethical dilemmas are present(Lin \& Ho, 2008). According to (Jones, 1991), Rest's (1986) four component model of ethical action that describes the process of ethical decision making is perhaps the most widely accepted model of ethical action in psychology. Through this model, ethical action is composed with 4 main variables: ethical awareness, ethical judgment, ethical behavior and ethical intention.

According to Rest (1986), the ethical decision making process is initiated with the first component, awareness. In this stage the agent recognizes that a situation presents a dilemma that is ethical in nature. That is, harm is a potential consequence of the behavior of the moral agent. In this stage, the person is realizes that he / she could do something that would affect the interest, welfare, or expectation of others. (McMahon \& Harvey, 2006). In the second stage - judgment stage - the agent evaluates various courses of action to determine which are morally right and which are morally wrong. In the third stage, intention, the agent selects a course of action to take. And in the final behavior stage, the agent engages in ethical or unethical action.

According to Lin \& Ho, 2008, ethical awareness includes interpreting the situation, role taking about how various actions might affect the parties concerned, imagining the cause effect chain of events, and being aware that there is a moral problem when one exist. Ethical judgment composites of judging which action would be most justifiable in a moral sense. Ethical intention includes the degree of commitment to taking the moral course of action, valuing moral values over other values, and taking personal responsibility for moral outcomes. Ethical behavior includes persisting in a moral task, having courage, overcoming fatigue and temptation, and implementing subroutines that serve a moral goal. (Rest, 1986)

According to (Butterfield, et al., 2000), ethical awareness and ethical judgment are two necessary components of ethical decision making because many difficult dilemmas ethically ambiguous, they can be viewed from a strategic perspective, an ethical perspective, or a perspective that involves a combination of both. (Lin \& Ho, 2008) In this study, researcher use general manager as the study group as they have to judge each ethical situation as well as judge what objectivity, integrity, and other ethical issues mean in the given situation, and then act according to their judgment.

Based on the review of the literature, authors believe that ethical decision making is a process by which individuals use their moral base to determine whether a certain issue is right or wrong based on the said four components during the process. From the findings, it indicates that moral fail to occur during a deficiency arises in either one of the said components as 
quoted by Rest et al (1986). Researchers believe that a specific portion of each component is necessary to carry out any line of moral action, as supported by Rest et al (1999). They pointed out that there is a complex interaction between the said four components. They argued that the four components are interacting and influencing each others. Each of these components is concerned importantly with the issues of right and wrong together with the obligation of morality. Typically, people believe that a good decision is the outcome of the careful thought and grounded with accepted values and management practices. Hence, ethical decision making involves gathering sufficient information and evaluating the results and potential implications of each option before arriving at the decision.

\subsection{Relationship between Personal Moral Philosophy and Ethical Decision Making}

From 1920, researchers have begun the study in the personality and psychology of individuals to search for a better instrument to measure and describe the differences between the individuals in term of their morality thinking and the morality guidelines which this guideline serve as the platform to influence the decision making and behaviour of an ethical nature (e.g. Kohlberg, 1969; Hogan, 1970, 1972; Rest, 1974). Ethics theorists agreed that without evaluate normative ethical standards from moral philosophy, it is impossible to develop the framework of ethical decision making, as quoted from Ferrell and Gresham (1985, p88). Hence, it provides the insight that moral philosophy may serve as the importance variables to influence an individuals' ethical decisions.

From the past studies, e.g.: Barnett et al (1994), findings indicated that idealism scores to be negatively correlated respondents' ethical decision in the vignettes. However, they found no significant relationship between respondents' relativism scores and the vignettes. This were supported by others studies ((K. Davis \& Frederick, 1984; A. Singhapakdi, et al., 1999) that showed idealism may have the strongest influence on individual's judgments and attitudes towards the ethical situation. From the findings, individuals scoring low in idealism and high in relativism were the most accepting of unethical behavior. The findings were consistent in another similar study that showed individuals scoring high in idealism and low in relativism to rate harmful research studies more harshly than individuals adopting other PMP. Barnett et al. (1994) discovered that in their study, individual's ethical judgment were not dependent on their PMP. They proposed that this may result from the scenario lacking of the salience of the subject. A person must first perceive the situation to have ethical significance before he or she can make an ethical evaluation. The explanation were consistently matched with the results of Forsyth's (1985) study, all four PMP are sensitive to consequences and conformity to norm information. Each tends to integrate information differently.

Previous findings indicate that highly relativistic individuals should not believe in moral absolutes. These individuals believe that the morality of an action is dictated by the circumstances of the situation. For those non relativistic individuals, they should rely on universal moral standards, law of the code of conduct when making ethical decision. Besides that, findings also indicated that idealistic individuals are likely to believe that moral actions will result in positive outcomes and that it is wrong to pursue a course of action that harms others. This was supported in the findings of idealism is positively correlated to concepts of 
justice and empathy for others, which individual who less idealistic will be more pragmatic and believe that causing harm to another party may be necessary to achieve the desired outcomes.

As stated by Forsyth (1994), the two dimensional of PMP model predicts that individuals who have different levels of idealism and relativism, will diverge when making decisions about ethical dilemmas if that situation contrasts with ethical codes and could potentially yield negative consequences, like harm or hurt to others, increased conflicts or unfair advantages (S. J. Forsyth, 1992). Forsyth stated that both absolutist (high idealism and low relativism) and exceptionist (low idealism and low relativism) individuals will judge actions harshly that break moral codes. While, both absolutist and situationist (high idealism and low relativism) individuals will respond harsher to actions that yield negative outcomes. Furthermore, PMP model contends at multivariate levels of absolutist individual tend to emphasize moral principles and express sensitively to harming others, so they will respond harshly to ethical dilemmas that violate moral codes and cause potential harm to patients. However, subjectivist will likely to be the most accepting of these actions.

Past researchers have proved that individuals' level of idealism and relativism can influence his or her ethical decision making ((M. A. Davis, Johnson, \& Ohmer, 1998; D. R. Forsyth, 1985; Rittenburg, Terri, \& Valentine, 2002), moral attitudes toward social issues (D. R. Forsyth, 1980) and judgments about ethics research (D. R. Forsyth \& Pope, 1984; Schminke \& Ambrose, 1997). However, the findings examining the link between moral thought and moral action are mixed. As argued by Forsyth and Berger, they failed to identify idealism and relativism as predictors of behavior. They found that idealism did influence moral behavior, but in a direction opposite to what they had predicted. Results demonstrated that individuals who high in idealism were those who most likely to lie and harm another person. Furthermore, previous studies also showed that individuals high in idealism and high in relativism were the most likely to engage in unethical tax behaviors as stated by (Cruz, Shafer, \& Strawser, 2000; Fleischman \& Valentine, 2003; D. R. Forsyth, 1980)

As stated by Forsyth (2002), there are three major intervening contingencies that may influence the relationship between an individual's PMP and his or her behavior: conditions of the environment, external pressure and personal needs. Individuals must aware and understand how his or her decision and the consequences of the action related to the moral norms. If he or she fails to perceive a particular decisions as having moral content, or if the pressure of a situation is great, then his or her PMP is less likely to be activated enough to influence his or her actions. Secondly, if the individual may successfully make a decision, however, it may fail to act in congruence with his or her moral decision because of external pressure. Finally, an indviduals if high in idealism is because of his or her need to avoid harming others, may be more likely to engage in unethical behavior as a means of helping others, as quoted by Forsyth (2002).

From the previous studies, authors concluded that idealism and relativism are playing an important role in affecting the process of ethical decision making as found in the past findings of Forsyth (1992), he has pointed out that these two dimension are strongly related to 
the business ethics. Besides that, Karande et al (2002) pointed that idealism has positive influences while relativism has the reverse influences toward the perceived moral intensity (D. R. Forsyth, 1992). Previous empirical findings indicates that more idealistic and less relativistic individuals tend to exhibit higher honesty and integrity than less idealistic and more relativistic individuals (Karande, et al., 2002)

\section{Conclusion and Discussion.}

Every social structure has a code of practices that constitutes its behavioural norms, that is, a set of rules governing what are acceptable and unacceptable behaviours. These rules are the moral philosophy of that social structure. When people find themselves in a situation in which there is a conflict or dilemma, the decision-making processes that they use to make the behavioural choices that follow are called ethical decision-making skills. Ethics, then, is the process whereby an individual, faced with a moral dilemma, arrives at a morally defensible decision. It is important to understand that the educative development of ethical reasoning skills neither represents nor advocates a prescribed moral position, and does not commit a student in advance to dogmatic solutions to all moral problems. Ethics, or ethical reasoning, is the process by which the most defensible resolution to a moral dilemma is sought.

A clearer and better understanding of the influences of PMP towards the process of EDM to adhere to the goals of organization and decreases the conflict arises whether in the workplace or during the daily life routines. The next stage of the study will use a quantitative methodology to examine the relationship of PMP and EDM of HR practitioners in Malaysia hotel industries, to explore the characteristics of PMP in the process of ethical decision making.

As the conclusion, most of the ethics theorists agree when an individual face situation with ethical content, he or she will apply ethical guidelines based on their personal moral philosophy, as supported by Ferrell and Gresham (1985) and Hunt and Vitell (1986). They believe that personal moral philosophy as an important factor to influence individuals' ethical decision. The relationship between PMP and EDM is an important factor in the development of ethical professional, especially in the business professional.

\subsection{Theoretical Implications}

Through this study, it insight authors to identify which dimensions of PMP will be the most effective in encouraging ethical behaviours. Authors believe that different levels of both dimensions significantly influence the entire process of the ethical decision making. Through the findings, it attempted to fill up the gap in the literature by examine the potential relationship between the PMP (idealism and relativism) and their ethical decision making.

\subsection{Managerial Implications}

The findings of the study can be incorporated in ethics training programs. Through the training, individuals are aware of the differentiation of thinking with regards to ethics and social responsibility, specifically in terms of idealism and relativism. Furthermore, through the training, it helps individuals to increase their sensitivity to differences in the moral 
philosophies of their counterparts and able to help them to anticipate the actions.

\section{References}

Ardagh, D., \& Macklin, R. (1998). Ethics and the human resource manager. Business and Professional Ethics Journal, 17(4), 61-78.

Beauchamp, T. L., \& Bowie, N. E. (1993). Ethical Theory and Business 4th. Eaglewood Cliffs, NJ: Prentice-Hall.

Beauchamp, T. L., \& Bowie, N. E. (2004). Ethical Theory and Business (7th ed.). New Jersey: Pearson Education,.

Butterfield, K. D., Trevino, L. K., \& Weaver, G. R. (2000). Moral awareness in business organizations: Influences of issues - related and social context factors. Human Relations, 53(7), 981-1018.

Carlson, D. S., Kacmar, K. M., \& Wadsworth, L. L. (2009). The Impact of Moral Intensity Dimensions on Ethical Decision Making: Assesing the Relevance of Orientation. Journal of Managerial Issues, 21(4), 534-551.

Cavanagh, G., Moberg, D., \& Velasquez, M. (1981). The ethics of organizational politics. Academy of management Review, 6(363-374).

Chen, M.-F., Pan, C.-T., \& Pan, M.-C. (2009). The joint moderating impact of moral intensity and moral judgement on consumer's use intention of pirated software. Journal of Business Ethics, 90, 361-373.

Cruz, C. A., Shafer, W. E., \& Strawser, J. R. (2000). A multidimensional analysis of tax practitioners' ethical jugdement. Journal of Business Ethics, 24, 223-244.

Davis, K., \& Frederick, W. C. (Eds.). (1984). Business and society: Management, Public Policy, Ethics (5 ed.). New York, NY: McGraw-Hill.

Davis, M. A., Johnson, N. B., \& Ohmer, D. G. (1998). Issues - contingent effects on ethical decision making: A cross cultural comparison. Journal of Business Ethics, 17, 373-389.

Dubinsky, A. J., \& Loken, B. (1989). Analyzing ethical decision making in marketing. Journal of Business Research, 19, 83-107.

Ferrell, O., \& Gresham, L. (1985). A contingency framework for understanding ethical decision making in marketing. The Journal of Marketing, 87-96.

Fleischman, G., \& Valentine, S. (2003). Professionals' tax liability and ethical evaluations in an equitable relief innocent spouse case. Journal of Business Ethics, 42(1), 27-44.

Forsyth, D. R. (1980). A taxanomy of ethical ideologies. Journal of Personality and Social Psychology, 39, 175-184.

Forsyth, D. R. (1985). Individual differences in information integration during moral judgment. Journal of Personality and Social Psychology, 49, 264-272. 
Forsyth, D. R. (1992). Judging the morality of business practices: the influence of personal moral philosophies. Journal of Business Ethics, 11, 461-470.

Forsyth, D. R., \& Nye, J. L. (1990). Personal moral philosophies and moral choice. Journal of Research in Personality, 24, 398-414.

Forsyth, D. R., Nye, J. L., \& Kelley, K. (1988). Idealism, Relativism and the Ethics of Carng. The Journal of Psychology, 122, 243-248.

Forsyth, D. R., \& Pope, W. R. (1984). Ethical ideology and judgments of social psychological research: multidimensional analysis. Journal of Personality and Social Psychology, 46(6), 1365-1375.

Forsyth, S. J. (1980). A taxamony of ethical ideologies. Journal of Personality and Social Psychology, 39(1), 175-184.

Forsyth, S. J. (1992). Judging the morality of business practices: The influence of personal moral philosophies. Journal of Business Ethics, 11, 461-470.

Hunt, S. D., \& Vitell, S. A. (1986). General Theory of Marketing Ethics. Journal of Macromarketing, 6, 5-16.

Jones, T. (1991). Ethical decision making by individuals in organizations: An issue-contingent model. Academy of management Review, 16(2), 366-395.

Karande, K., Rao, C. P., \& Singhapakdi, A. (2002). Moral philosophiesof marketing managers: A comparison of American, Australian, and Malaysian cultures. European Journal of Marketing, 36(7/8), 768-791.

Lin, C.-Y., \& Ho, Y.-H. (2008). An examination of cultural differences in ethical decision making using the multidimensional ethics scale. Social Behavior and Personality, 36(9), 1213-1222.

Malloy, D. C., \& Fennell, D. A. (1998). Ecotourism and ethics: moral development and organization cultures. Journal of Travel Research, 36, 47-56.

Mcdonald, G. M., \& Kan, P. C. (1997). Ethical perceptions of expatriate and local managers in Hong Kong. Journal of Business Ethics, 16, 1605-1623.

McMahon, J. M., \& Harvey, R. J. (2006). An analysis of the factor structure of Jones' moral intensity construct. Journal of Business Ethics, 4(381-404).

Musser, S. J., \& Orke, E. A. (1992). Ethical values systems: A typology. Journal of Applied Behavioral Science, 28, 348-362.

Peterson, D., Rhoads, A., \& Vaught, B. C. (2001). Ethical beliefs of business professionals: A study of gender, age, and external factors. Journal of Business Ethics, 31(3), 225-232.

Rest, J. R. (1986). Moral Development: Advances in research and theory.

Rittenburg, Terri, \& Valentine, S. R. (2002). Spanish and American Executives' Ethical 


\section{Macrothink}

Journal of Management Research

ISSN 1941-899X 2011, Vol. 3, No. 2: E16

Judgements and Intensitions. Journal of Business Ethics, 38, 291-306.

Schminke, M., \& Ambrose, M. L. (1997). Asymmetric Perceptions of Ethical Frameworks of Men and Women in Business and Nonbusiness Settings. Journal of Business Ethics, 16, 719-729.

Singhapakdi, A., Vitell, S. J., \& Franke, G. R. (1999). Antecedents, consequences and mediating effects of perceived moral intensity and personal moral philosophies. . Journal of the Academy of Marketing Sciences, 27, 19-36.

Singhapakdi, A., Vitell, S. J., \& Leelakuthanit, O. (1994). A cross cultural study of moral philosophies, ethical perceptions and judgements: A comparison of American and Thai Marketers. International Marketing Review, 11, 65-78.

Stevens, B. (2001). Hospitality Ethics: Responses from Human Resource Directors and Students to Seven Ethical Scenarios. Journal of Business Ethics, 30, 233-242.

Trevino, L. K. (1986). Ethical Decision Making in Organization: A Person - Situation Interactionist Model. The Academy of Management Review, 11(3), 601-617.

\section{Copyright Disclaimer}

Copyright reserved by the author(s).

This article is an open-access article distributed under the terms and conditions of the Creative Commons Attribution license (http://creativecommons.org/licenses/by/3.0/). 